\title{
Should social accountability be considered as one of the key benchmarks for excellence in medical education?
}

\author{
Md Anwarul Azim Majumder
}

Director of Medical Education, Faculty of Medical Sciences The University of the West Indies Cave Hill Campus Barbados.

".......schools are expected to document social accountability plans in their organization and functions; document social accountability actions in their education and research program activities; and demonstrate positive impacts of their education, research, service, graduates, and partnerships on the health care and health of their community, region, and nation". ${ }^{1}$

Medical education in $20^{\text {th }}$ century focused more on scientific approaches and curative care and less on prevention and population-based approaches to training physicians . ${ }^{1-4}$ This is because of influence of the Flexner Report on medical education of $1910 .{ }^{3}$ Medical schools are now in the $21 \mathrm{st}$ century dealing with different set of challenges and priorities: "improving quality, equity, relevance and effectiveness in health care delivery; reducing the mismatch with societal priorities; redefining roles of health professionals; and providing evidence of impact on people's health status". 5 To overcome these challenges, the Global Consensus for Social Accountability of Medical Schools were developed in 2010 and defined socially accountable medical school as one that: "responds to current and future health needs and challenges in society, re-orientates its education, research, and service priorities accordingly, strengthens governance and partnerships with other stakeholders and uses evaluation and accreditation to assess their performance and impact". 5

In recent years, there is growing interest worldwide in social accountability for medical and other health professional schools to evaluate medical school performance and education quality. ${ }^{1,6,7}$ Medical schools should produce competent and need-based physicians who will be able to work in their community and make a positive impact on people's health. The concept of "Social Accountability of Medical Schools" was proposed by Boelen and Heck in 1995 and the concept was defined as: "The obligation for medical schools to direct their education, research and service activities towards addressing the priority health concerns of the community, region and/or nation they have a mandate to serve". ' Social accountability is now considered as one of the most important criteria to recognize excellence in medical education. ${ }^{8}$ Medical schools worldwide using the concepts and principles to plan, implement and evaluate educational programs. The principles of social accountability have also been highlighted in many educational reports and documents. ${ }^{9}$ Medical schools, as a result, are more focused to train and produce graduates who are "fit for purpose" to deal with priority health concerns of society. Medical schools are putting more emphasis on community-based and community-oriented medical education by "reflecting on current and future health needs and challenges in society, interprofessional collaboration and emphasizing on impact". ${ }^{10}$ Medical students are key stakeholder and they should be involved and engaged in all social accountable actions and activities - "from the selection and admissions process to the curriculum and teaching methods". ${ }^{10}$ The International Federation of Medical Students' Associations (IFMSA) developed a "Students' Toolkit on Social Accountability in Medical Schools" which highlight the core principles and strategies to implement guidelines prescribed by the WHO to design best medical education training and practices to improve the health of the population. ${ }^{11}$

Accreditation is considered as one of the powerful tools for quality control and improvement of medical education. 12-18 Accreditation focuses on "the certification of the suitability of medical education programmes, and of the competence of medical schools in the delivery of medical education". ${ }^{19}$ In accreditation, a statutory body evaluates and recognises a medical school and/or its programme with approved guidelines prescribed by recognized authorities e.g. World Federation for Medical Education (WFME). The standards are used worldwide and have been adopted to local needs in most parts of the world. They are framed to specify attainment at two levels: basic standards or minimum requirements and standards for quality development. ${ }^{19}$ The concept of social accountability is embedded in all parts of the WFME standards documents. The guidelines for Accreditation of Medical Schools in Countries of the South-East Asia Region have been developed based on WHO/WFME Guidelines with a hope that the national accrediting agencies of member countries will follow these principles to develop their own tools for institutional accreditation. ${ }^{20}$

To achieve excellence in medical education, medical schools should reorient its curriculum based on the priority health needs of the country and challenges to health systems need-based doctors. Moreover, effective intra- and inter-sector collaborations should be developed with proper benchmarks (e.g. accreditation) to examine the social accountability of medical schools to improve patient care, education, and research. ${ }^{1,21}$

Correspondence: Dr. Md. Anwarul Azim Majumder, Director of Medical Education, Faculty of Medical Sciences, The University of the West Indies, Cave Hill Campus. Barbados. E-mail: azim.majumder@cavehill.uwi.edu. 


\section{References}

1. Rourke J. Social Accountability: A Framework for Medical Schools to Improve the Health of the Populations They Serve. Acad Med. 2018;93:1120-24.

2. Rourke J. Social accountability of medical schools. Acad Med. 2013;88:430.

3. Irby DM, Cooke M, O'Brien BC. Calls for reform of medical education by the Carnegie Foundation for the Advancement of Teaching: 1910 and 2010. Acad Med. 2010;85:220-7.

4. Majumder AA, D'Souza U, Rahman S. Trends in medical education: challenges and directions for need-based reforms of medical training in SouthEast Asia. Indian J Med Sci 2004; 58: 369-80

5. The Network. Global Consensus for Social Accountability of Medical Schools. 2010. https:// thenetworktufh.org/gcsa/ (accessed June 2018)

6. National Academies of Sciences, Engineering, and Medicine. A Framework for Educating Health Professionals to Address the Social Determinants of Health. Washington, DC: National Academies Press, 2016.

7. Boelen C, Heck, JE. Defining and measuring the social accountability of medical schools. Geneva: World Health Organization, 1995.

8. Boelen R, Woollard B. Social accountability and accreditation: a new frontier for educational institutions Med Educ 2009;43:887-94.

9. World Health Organization. Global strategy on human resources for health: workforce 2030. Geneva: WHO, 2016.

10. Dijk S, Björg Pálsdóttir, Simone J Ross, Jeremy Glasner, Mohsna Bhiri, Rita Ramalho. Students' Toolkit on Social Accountability in Medical Schools. Amsterdam: IFMSA, 2017.

11. The International Federation of Medical Students' Associations (IFMSA). Global Policy on Medical Education. Amsterdam: IFMSA, 2016.
12. Blouin D, Tekian A, Kamin C, Harris IB. The impact of accreditation on medical schools' processes. Med Educ. 2018;52(2):182-91.

13. van Zanten M, Norcini JJ, Boulet JR, Simon F. Overview of accreditation of undergraduate medical education programmes worldwide. Med Educ. 2008;42:930-7.

14. Cueto J Jr, Burch VC, Adnan NA, Afolabi BB, Ismail $\mathrm{Z}$, Jafri $\mathrm{W}$, et al. Accreditation of undergraduate medical training programs: Practices in nine developing countries as compared with the United States. Educ Health (Abingdon). 2006;19:207-22

15. Boulet J, van Zanten M. Ensuring high-quality patient care: The role of accreditation, licensure, specialty certification and revalidation in medicine. Med Educ. 2014;48:75-86.

16. Davis DJ, Ringsted C. Accreditation of undergraduate and graduate medical education: How do the standards contribute to quality? Adv Health Sci Educ Theory Pract. 2006;11:305-13

17. Al Alwan I. Is accreditation a true reflection of quality? Med Educ. 2012;46:542-4.

18. Blouin D1, Tekian A. Accreditation of Medica Education Programs: Moving From Student Outcomes to Continuous Quality Improvement Measures. Acad Med. 2018;93(3):377-83.

19. World Federation for Medical Education Accreditation. https://wfme.org/accreditation/ (accessed June 2018)

20. World Health Organization. Guidelines for Accreditation of Medical Schools in Countries of the South-East Asia Region. New Delhi: WHO, 2009.

21. Majumder MAA. Issues and priorities of medical education research in Asia. Ann Acad Med Singapore 2004;33:257-63. 